\title{
Cloning and characterization of a new $\beta$-Glucosidase from a metagenomic library of Rumen of cattle feeding with Miscanthus sinensis
}

Yadan Li ${ }^{1,2}$, Ning Liu ${ }^{2,3}$, Hui Yang ${ }^{1,2}$, Fei Zhao ${ }^{1,2}$, Ye Yu ${ }^{1,2,4}$, Yun Tian ${ }^{1,2^{*}}$ and Xiangyang $\mathrm{Lu}^{1,2^{*}}$

\begin{abstract}
Background: The study on the second generation bio-fuel is a hot area of current research of renewable energy. Among series of key points in this area, the role of $\beta$-glucosidase in the degradation of intermediate gluco-oligosaccharides limits the rate of the complete saccharification of lignocellulose.

Results: In this study, a new $\beta$-glucosidase gene, unglu135B12, which was isolated from a metagenomic library of rumen of cattle feeding with Miscanthus sinensis by the function-based screening, encodes a 779 amino acid polypeptide that contains a catalytic domain belonging to glycoside hydrolase family 3 (GH3). It was recombinantly expressed, purified and biochemically characterized. The recombinant $\beta$-glucosidase, unglu135B12, displayed optimum enzymatic activity at $\mathrm{pH} 5.0$ at $38^{\circ} \mathrm{C}$, and showed the highest specific activity of $2.5 \times 10^{3} \mathrm{U} / \mathrm{mg}$ under this optimal condition to p-nitrophenyl- $\beta$-D-glucopyranoside (pNPG), and its $\mathrm{Km}$ and Vmax values were $0.309 \mathrm{mmol} / \mathrm{L}$ and $7.292 \mu \mathrm{mol} / \mathrm{min}$, respectively. In addition, the presence of $\mathrm{Ca}^{2+}, \mathrm{K}^{+}, \mathrm{Na}^{+}$slightly improved $\beta$-glucosidase activity of unglu135B12 by about 5\%, while about $10 \sim 85 \%$ loss of $\beta$-glucosidase activity was induced by addition of $\mathrm{Mn}^{2+}$, $\mathrm{Fe}^{3+}, \mathrm{Zn}^{2+}, \mathrm{Cu}^{2+}$. Interestingly, unglu135B12 was activated by glucose at the concentration lower than $40 \mathrm{mM}$.
\end{abstract}

Conclusions: Our findings indicate that unglu135B12 is a new $\beta$-glucosidase derived from rumen of cattle, and it might be a potent candidate for saccharification of lignocellulose in industrial application.

Keywords: $\beta$-glucosidase, Rumen, Miscanthus sinensis, Metagenomic library

\section{Background}

The study on the second generation bio-fuel, which can be constantly derived from the waste of agriculture and forestry and the widespread distribution of non-food plants, is a hot area of current research of renewable energy [1,2]. Among non-food plants, as the raw material of bio-fuel, Miscanthus sinensis has been focused on in recent years as an ideal bio-source plant. This fiber-rich plant is widely distributed around South East Asia, and it's also a common specie in China [3]. However, the complexity of lignocellulose of its cell wall makes the plant very difficult to be degraded [4]. Thus, it is urgent to explore new strong functional enzymes to solve the

\footnotetext{
*Correspondence: tianyun79616@163.com; xiangyangcn@163.com ${ }^{1}$ College of Bioscience and Biotechnology, Hunan Agricultural University, Changsha 410128, China

${ }^{2}$ Hunan Agricultural Bioengineering Research Institute, Changsha 410128, China

Full list of author information is available at the end of the article
}

key problem in degradation of this plant, and to discover an economical way for the production of renewable bio-fuel from Miscanthus sinensis.

The conversion of the most abundant part of fiber, cellulose, into bio-fuel will depend on the synergistical hydrolysis of enzymes at least including three main cellulases: endo- $\beta$-1,4-glucanase (EC3.2.1.4), cellobiohydrolase (EC3.2.1.91) and $\beta$-glucosidase (EC3.2.1.21) [5]. $\beta$-glucosidase is widely distributed in nature $[6,7]$, which catalyses the cleavage of the glycosidic bonds existing in disaccharides, oligosaccharides and alkyl- or aryl- $\beta$-glucosides [8]. Although $\beta$-glucosidase does not act on cellulose directly, it is of great importance in cellulose deconstruction by eliminating cellobiose inhibition on endoglucanases and exoglucanases, allowing the cellulolytic enzymes to function more efficiently $[5,9]$. Therefore, the activity of $\beta$-glucosidase is considered as the rate-limiting factor in cellulose degradation. 
The low efficiency of $\beta$-glucosidases discovered in previous studies may be responsible for the high cost of bio-fuel production from lignocellulosic biomass [10], identification of new efficient $\beta$-glucosidases is thus important and necessary. Ruminants carry out a foregut fermentation that digests plant polysaccharides materials by a complicated and efficient microbial process [11]. Therefore, the habitat in rumen represents a rich hotspot for exploring diverse functional enzymes which could be used in lignocellulose degradation. Considering the fact that more than $85 \%$ of ruminal microbes remains uncultured, metagenomic technology, avoiding from pure culture, has drawn more attention during the study of finding new cellulolytic enzymes from this special environment [12].

Metagenomic strategy had been successfully employed in identification of new biocatalytic enzymes encoding genes from the uncultured component of microbial communities from a variety of environmental samples $[13,14]$. In general, metagenomic method involves the extraction of metagenomic DNA from uncultured samples, the construction of the metagenomic libraries and the screening for the aimed genes [13]. This cultureindependent method is able to avoid the limitation of the pure cultivation method, and many new $\beta$-glucosidases encoding genes have been obtained by means of metagenomics [15-17].
It had been demonstrated that the ratio of cellolytic bacteria was increased in large intenstine of Miscanthus sinensis feeding cattle [18]. Meanwhile, our unpublished result showed that the ratios of cellolytic bacteria and fungi in rumen were also increased due to the sole forage of Miscanthus sinensis. Therefore, exploring new cellolytic enzymes encoding gene from Miscanthus sinensis feeding cattle exhibit more potentiality. The aim of the present study was to identify new gene encoding $\beta$-glucosidase from total DNA isolated from ruminal microbes of Xiangxi yellow cattle fed on Miscanthus sinensis using the metagenomic techniques. Through function-based screening of the metagenomic library, one new $\beta$-glucosidase gene was obtained. The recombinant enzyme was overexpressed in Escherichia coli BL21(DE3) and investigated for the enzymatic properties.

\section{Results}

Construction and evaluation of the matagenomic library from microbes in Xiangxi yellow cattle rumen

To identify new $\beta$-glucosidase from metagenomic library, the strategy was described in Figure 1A. Rumen content samples were collected from Xiangxi yellow cattle in Hunan province. A fosmid library was constructed with metagenomic DNA isolated from microbes of rumen samples, containing 20,160 clones. The average insert

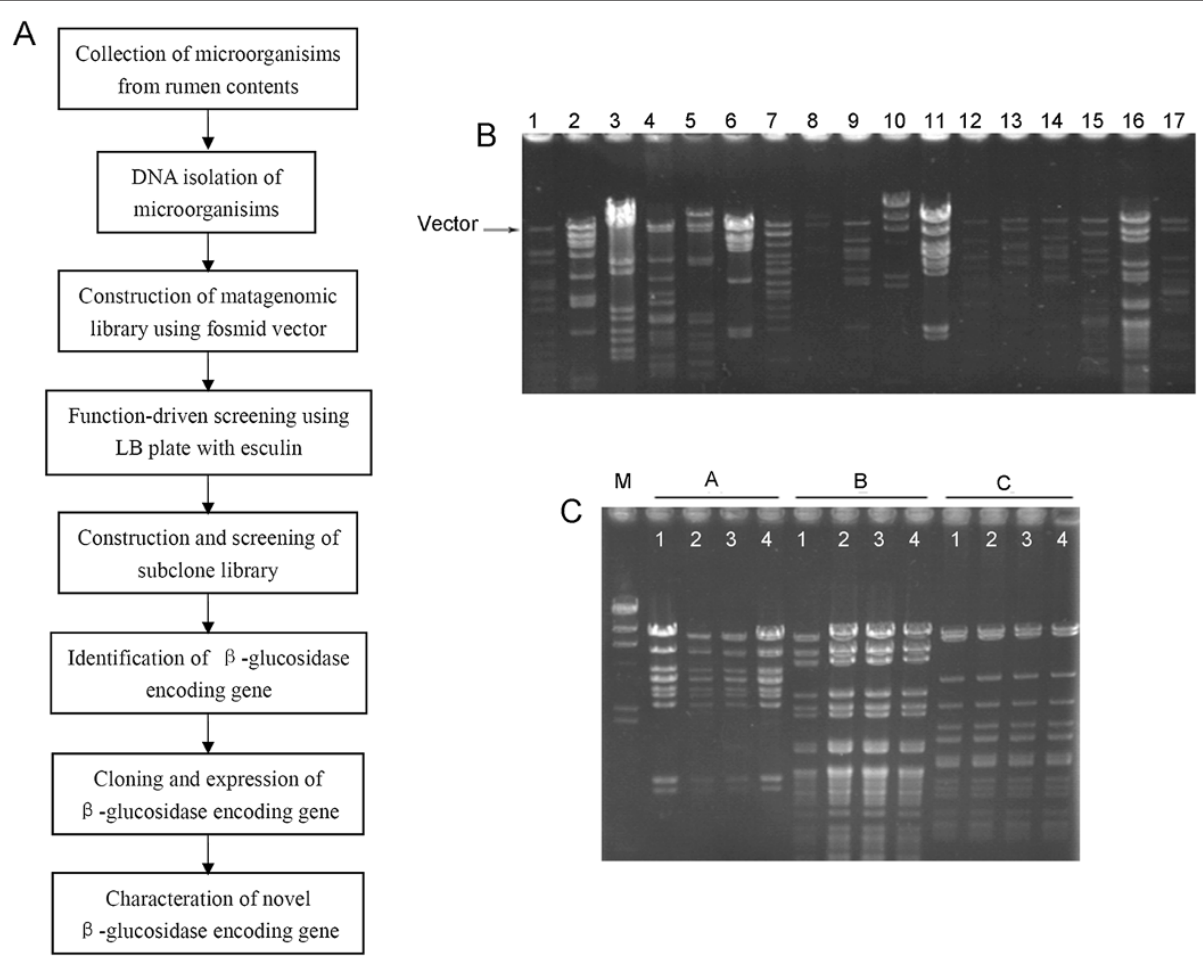

Figure 1 Identification of a positive $\beta$-glucosidase functional clone 135B12 from metagenomic library of Miscanthus sinensis fed cattle's ruminal inhabitants. A. Strategy of obtaining of new $\beta$-glucosidase from metagenomic library. $\mathbf{B}$. The volume of metagenomic library. C. Stability of exogenous gene in the library after subcultures $(\mathbf{A}, \mathbf{B}, \mathbf{C}$ : digestive pattern of fosmid DNA of three indipendent clones from the library by EcoR I and Hind III; 1-4: mean four times of subcultures). 
size of clones was about $30 \mathrm{~kb}$, and the full size of the library was estimated to be $600 \mathrm{Mb}$ (Figure 1B). The stability of this metagenomic library was reliable according to the result of restriction endonuclease analysis that the insert fragments of three clones which were chosen randomly from the library were in accord with the original one after four times of subcultures (Figure 1C). Furthermore, the reliability of the present metagenomic library was also proved by the results of random sequencing of 92 clones' insert fragments (Additional file 1: Table S1). One singlet of all had $\geq 97 \%$ similarity with Bacteroides thetaiotaomicron and two singlets had $\geq 97 \%$ similarity with uncultured Bacteria, which demonstrated the present metagenomic library was valid, while, other eighty-nine singlets didn't have high homology with known sequences which perfectly confirmed that the library possessed great novelty (Additional file 1: Table S1).

\section{Annotation of $\beta$-glucosidase gene unglu135B12}

All of the clones were transferred to the screening plates for $\beta$-glucosidase activity. A clone expressing relatively strong $\beta$-glucosidase activity was obtained, named 135B12. Due to the average length of insert sequence of $135 \mathrm{~B} 12$ was about $32 \mathrm{~kb}$, sequence of the new gene encoding $\beta$-glucosidase was not fit for direct location. Thus subclone library was further constructed using the pUC19 vector to yield smaller fragments. After the screening by the same activity-based method as mentioned above, the positive subclone was sequenced. The length of predicted ORF was 2340 bp encoding a protein of 779 amino acids (Figure 2A). The new sequence had been submitted to NCBI, and the genebank access number was JX962691. The sequence of 2340 bp was shortly named as Unglu135B12, and the encoded protein was Unglu135B12 accordingly.

\section{Analyses of predicted $\beta$-glucosidase sequence and domain structures}

The theoretical molecular mass of Unglu135B12 is $84.0 \mathrm{kDa}$, and the value of $\mathrm{pI}$ is 6.0 according to the analysis of DNAStar. Sequence analysis with SMART indicated that the putative protein has one glycosyl hydrolase family 3 domain (from 71 to 290 amino acid) and one glycosyl hydrolase family $3 \mathrm{C}$ terminal domain (from 356 to 642 amino acid) (Figure 2B). Additionally, conserved domains search on NCBI also revealed that Unglu135B12 comprised these two conserved domains (figure didn't show in this paper). Thus Unglu135B12 was probably a GH3 $\beta$-glucosidase. Information of phylogenetic tree showed it exhibited from $57 \%$ to $62 \%$ sequence identities to homologous proteins derived from bacteria of Bacteroidetes phylum (e.g. Prevotella bergensis) (Figure 2C).

\section{Expression and characterization of Unglu135B12}

In order to characterize Unglu135B12, unglu135B12 was cloned into pET28a (+) and heterologously expressed in BL21 and purified. The western bolt detection showed the positions of expressed protein and purified protein, which were in accordance with the predicted MW value (Figure 3A). Furthermore, the purified Unglu135B12 was tested on the functional screening plate and it was demonstrated that the heterologous protein before/after purification and dialyzed protein were still with the $\beta$-glucosidase activity (Figure 3B).

To determine enzymatic characteristics of this purified putative GH3 $\beta$-glucosidase, pNPG was used as substrate for testing the activity of $\beta$-glucosidase. As shown in the present data, the optimal temperature was $38^{\circ} \mathrm{C}$ and the optical $\mathrm{pH}$ was 5.0 (Figure $4 \mathrm{~A}$ and $\mathrm{C}$ ), with the specific activity of $2.5 \times 10^{3} \mathrm{U} / \mathrm{mg}$. The relative activity of Unglu135B12 still reserved $60 \%$ when placed it under $\mathrm{pH} 5.0-6.0$ at $4{ }^{\circ} \mathrm{C}$ for $24 \mathrm{~h}$. The stability features of Unglu135B12 were not very satisfied, as it was stable only in a narrow range of a battery of temperatures and pHs (Figure 4B and D).

The addition of $\mathrm{Ca}^{2+}, \mathrm{K}^{+}, \mathrm{Na}^{+}$slightly enhanced $\beta$ glucosidase activity of Unglu135B12 by about $5 \%$ and about $10-85 \%$ loss of $\beta$-glucosidase activity was induced by addition of $\mathrm{Mn}^{2+}, \mathrm{Fe}^{3+}, \mathrm{Zn}^{2+}, \mathrm{Cu}^{2+} \cdot \mathrm{Mg}^{2+}$ had little effect on activity of Unglu135B12 (Figure 4E).

The activity of Unglu135B12 towards pNPG was enhanced by glucose at concentrations lower than $40 \mathrm{mM}$ (Figure $4 \mathrm{~F}$ ). In the presence of $40 \mathrm{mM}$ glucose, the activity of Unglu135B12 increased to a maximum value with 9.6\% more than that of the control without glucose. With glucose further increasing, the enzyme activity was gradually inhibited.

The reaction kinetic parameters of the purified enzyme were measured from double reciprocal Lineweaver-Burk plots. This putative $\beta$-glucosidase had a $K_{m}$ value of $0.309 \mathrm{mmol} / \mathrm{L}$, a $V \max$ value $7.292 \mu \mathrm{mol} / \mathrm{min}$.

\section{Analysis of 3D structure and substrate docking}

Based on structural analysis, Unglu135B12 was composed by three domains: an $\alpha / \beta$ barrel, an $\alpha / \beta$ sandwich and a fibronectin-like domain at carboxyl-terminal (Figure 5A). It was supposed that $\alpha / \beta$ barrel and $\alpha / \beta$ sandwich were able to contribute each one of the two catalytic residues, while, the function of fibronectin-like domain was still unclearly and this domain was not present in all enzyme of GH3 family [19]. Molecular docking was conducted with the substrate pNPG by the tool of Discovery Studio LibDock based on this lowest-energy model. In the light of the need of clearer description of the relative location between enzyme and substrate, then it was amplified appropriately as Figure 5B. Moreover, Figure $5 \mathrm{C}$ indicated that some key residues existed around pNPG in the 
A

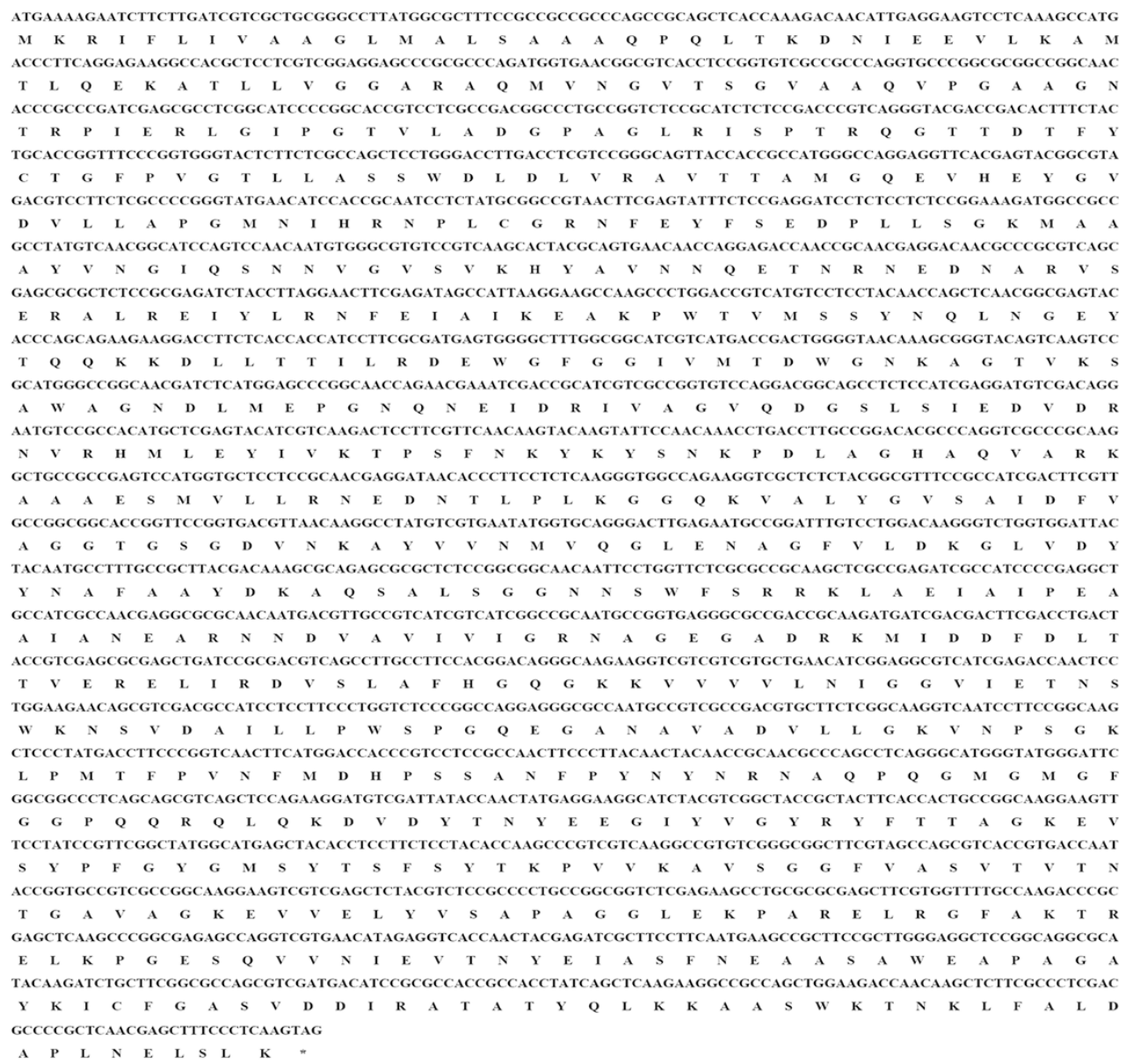

B

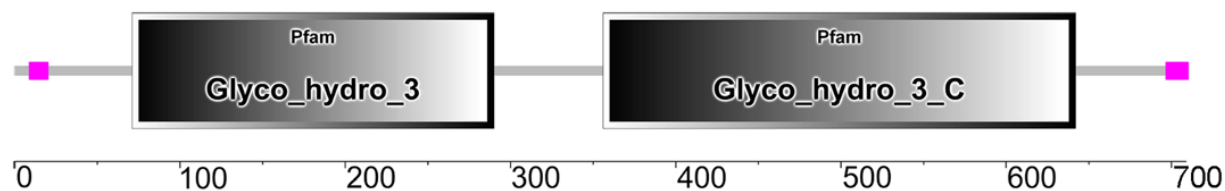

C

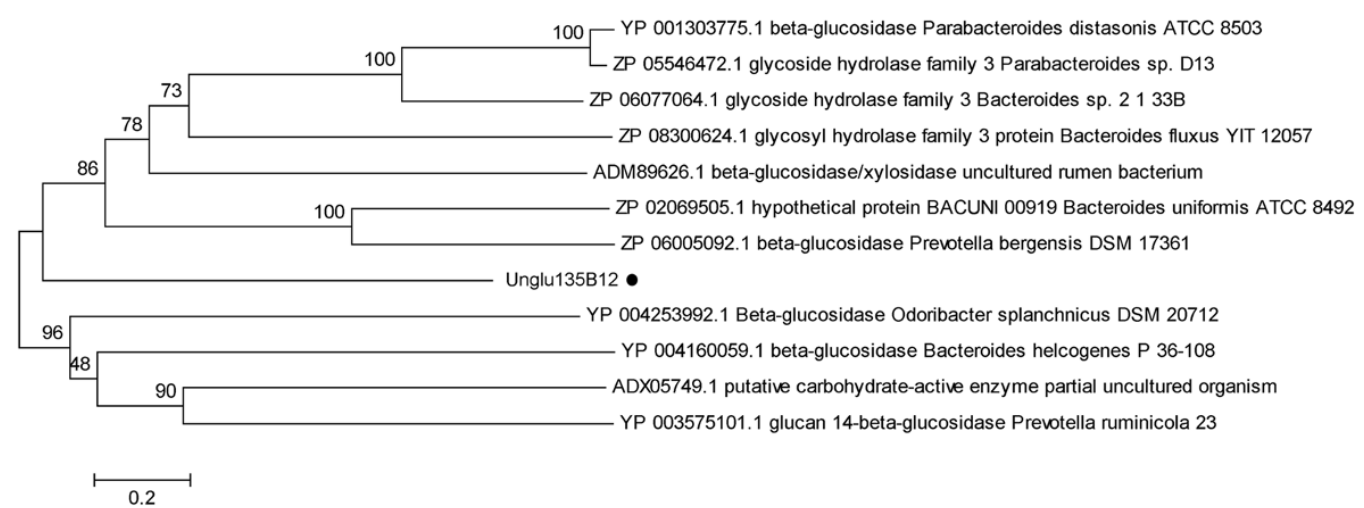

Figure 2 Characterization of amino acid sequence of Unglu135B12. A. amino acid sequence of Unglu135B12. B. Predicted modular architecture of Unglu135B12. C. Phylogenetic relationship of Unglu135B12 with related proteins. The scale bar corresponds to a genetic distance of 0.2 substitutions. 

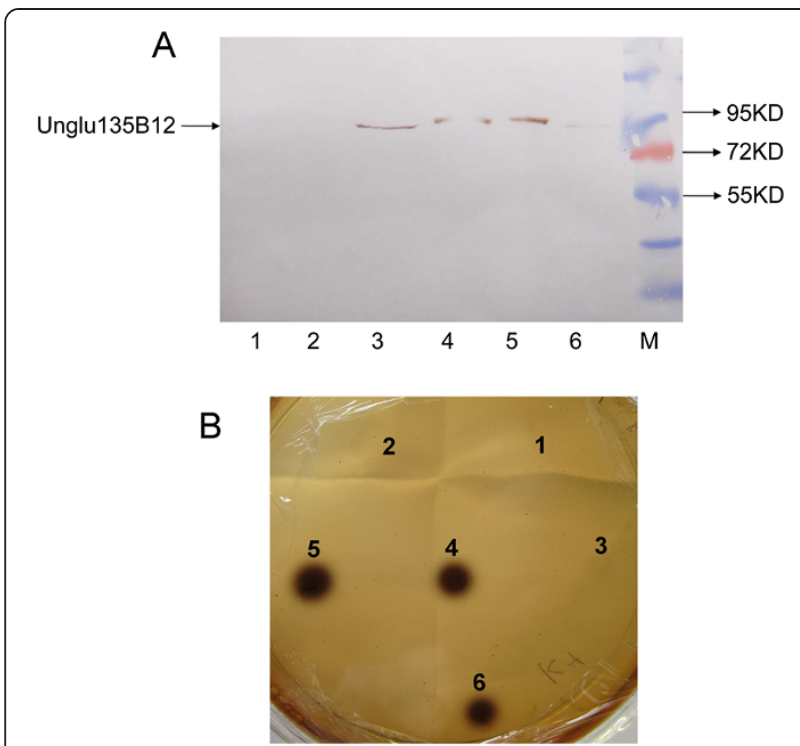

Figure 3 Characterization of Unglu135B12. A. Characterization of Unglu135B12 by western blot. Lane 1. Crude extract of BL21 (DE3) carrying pET28a (+) vector; Lane 2: IPTG-uninduced crude extract of BL21 (DE3) carrying pET-Unglu135B12; Lane 3: IPTG-induced crude extract of BL21 (DE3) carrying pET-Unglu135B12; Lane 4: Eluted Unglu135B12 protein after purification by Ni-NTA His · Bind Resins; Lane 5: Dialyzed Unglu135B12 protein; Lane 6: Flow through; Lane M: protein Marker. B. Functional verification of purified Unglu135B12. 1. Crude extract of BL21 (DE3); 2: Crude extract of BL21 (DE3) carrying pET28a (+) vector; 3: IPTG-uninduced crude extract of BL21 (DE3) carrying pET-Unglu135B12; 4: IPTG-induced crude extract of BL21 (DE3) carrying pET-Unglu135B12; 5: Eluted Unglu135B12 protein after purification by Ni-NTA His · Bind Resins; 6: Dialyzed Unglu135B12 protein.

model, which could probably form hydrogen bonds and phosphoanhydride bonds and played irreplaceable roles in the catalytic pocket (Figure 5C).

\section{Discussion}

In this present work, we used Miscanthus sinensis, a promising cellulosic energy crop, as the plant substrate for feeding experimental animal. To explore new $\beta$-glucosidase gene from the microbial communities of these Miscanthus sinensis fed cattle, a metagenomic library containing about 20,160 clones was constructed, which was screened by function-based method. Consequently, the gene Unglu135B12 was identified as the potential candidate gene. The purified protein Unglu135B12 showed high specific activity to the substrate pNPG, and its activity could be influenced by different irons. Besides, the inhibition of glucose on Unglu135B12 began to appear only when the concentration of glucose was more than $40 \mathrm{mM}$. These data provided strong evidence to support the feasibility of searching functional enzyme for mono-/ polysaccharides degradation from rumen habitat. Rumen habitats harbor a vast microbial diversity, including various anaerobic bacteria, archaea and fungi that are different from those found in water, soil or other environments. This special microbial community is closely related to the fiber-rich diet, due to the synergistic actions of cellulase, hemicellulase, ligninolytic enzymes and $\beta$ glucosidase derived from ruminal microbes, and fullfills the degradation of complex structure of plant in animal's diet $[4,20]$. Therefore, the metagenomic library in our work distinguished itself as an ideal extensive resource for searching cellulolytic enzymes or other enzymes related to this degradation process.

On the basis of phylogenetic analysis, Unglu135B12 was mostly closed to one beta-glucosidase from Prevotella bergensis, belonging to Bacteroidetes (Figure 2C). This indication was in line with the results of our unpublished studies, in which we comparatively analyzed the phylogenetic relationship of ruminal bacteria between Miscanthus sinensis fed cattle and mixed forage fed cattle and found that the proportion of Bacteroidetes was increased significantly induced by the sole diet of Miscanthus sinensis. So it emphasized again the relevance between feeding of Miscanthus sinensis and rise trend of Bacteroidetes in rumen. With the function of glycosyl hydrolase, Bacteroidetes play key roles in the decomposition of carbohydrate polymers and proteins in digestive system of mammal [21,22]. In the light of this point, it's worthy to further detect new glycosyl hydrolase from the present microbial metagenomics library.

In addition, it was said that microbial genomes often contain a substantial number of glycosyl hydrolase (GH) genes, many of which could be induced by different carbon sources. The evidence from conserved domain analysis strongly indicated that Unglu135B12 was a member of glycosyl hydrolase family 3 (GH3). GH3 is one of the largest GH families with more than 4800 sequences in the CAZy database (http://www.cazy.org) and the relative abundance and distribution of GH3 in the metagenome from the bovine rumen microbiome is $18.4 \%$ [23].

After the western blot analysis using the specific anti-his tag antibody, the molecular mass of the rumen microbial protein was recognized as about $85 \mathrm{kD}$, in consistent with the predicted value, which suggested that this protein was probably a monomeric protein. Moreover, the purified $\beta$-glucosidase Unglu135B12 from the heterologous expression system were identified that it efficiently hydrolyzed pNPG within a narrow $\mathrm{pH}$ range of 5.0-6.0, and had optimal activity at $38^{\circ} \mathrm{C}$, which indicated the native Unglu135B12 protein might play an active role under in vivo conditions in the cattle rumen. However, these features of the recombinant protein might hinder its industrial application. Given the limitation of Unglu135B12 in industrial production, it's worthy to improve its stability of $\mathrm{pH}$ and temperature by 


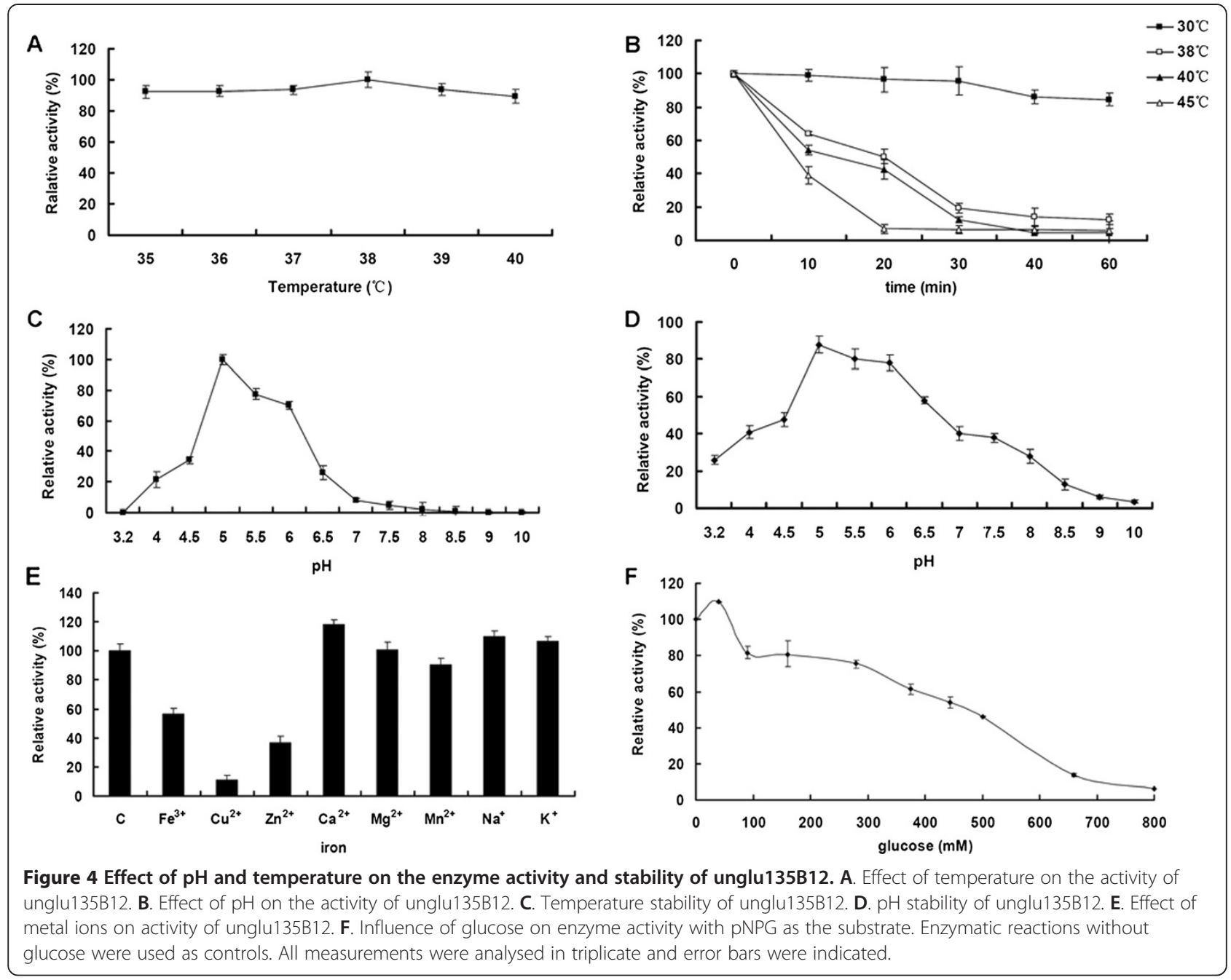

biotechnological methods such as site-directed mutagenesis, codon randomisation [24] or immobilization techniques [25]. Therefore, with the help of the prediction by homology modeling and molecular docking, sitedirected mutagenesis against the key residues could be considered as a new orientation in further research. While, the specific activity of Unglu135B12 against pNPG was measured as $2.5 \times 10^{3} \mathrm{U} / \mathrm{mg}$ at $\mathrm{pH} 5.0$ when assayed at $38^{\circ} \mathrm{C}$. It was considered as a relatively high value compared with other $\beta$-glucosidases found in uncultured microbes or pure-isolated microbes $[15,26]$. Besides, addition of $\mathrm{Ca}^{2+}, \mathrm{K}^{+}, \mathrm{Na}^{+}$could enhance its activity to $105 \%$. Based on this information, it's hopefully to achieve more enhancement of Unglu135B12's activity. Furthermore, most of the microbial $\beta$-glucosidases reported to date are competitively inhibited by glucose, while several $\beta$-glucosidases from a few fungi and yeasts show high glucose tolerance $[27,28]$. Unglu135B12 is activated by glucose at concentrations below $40 \mathrm{mM}$ and remains more than $75 \%$ activity with glucose at concentrations of $280 \mathrm{mM}$. In further study, the tolerance to glucose of unglu135B12 could be probably improved by protein engineering [29].

Overall, the reason why unglu135B12 exhibited these characteristics described above could be attributed to its source. Consistent with other $\beta$-glucosidases obtained by metagenome method from herbivore's digestive tract, their optimal $\mathrm{pH}$ and temperature were in a narrow range which similar to their natural environment $[15,26]$. In addition, it's worth mentioning that the activity of unglu135B12 is significantly higher than that of the $\beta$ glucosidases from rabbit cecum [26] and yak rumen [15], moreover, the unglu135B12 still showed tolerance to glucose. These points might indicate more potentiality of further directed mutagenesis on unglu135B12.

\section{Conclusions}

The more effective $\beta$-glucosidase could definitely convert cellobiose into glucose more conveniently and economically, and the combination of this new $\beta$-glucosidase and 
A
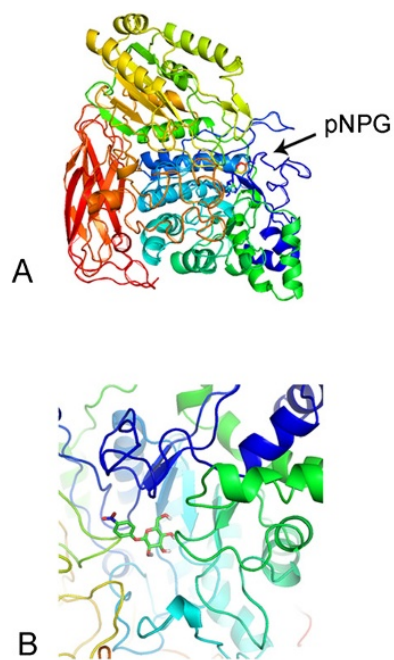

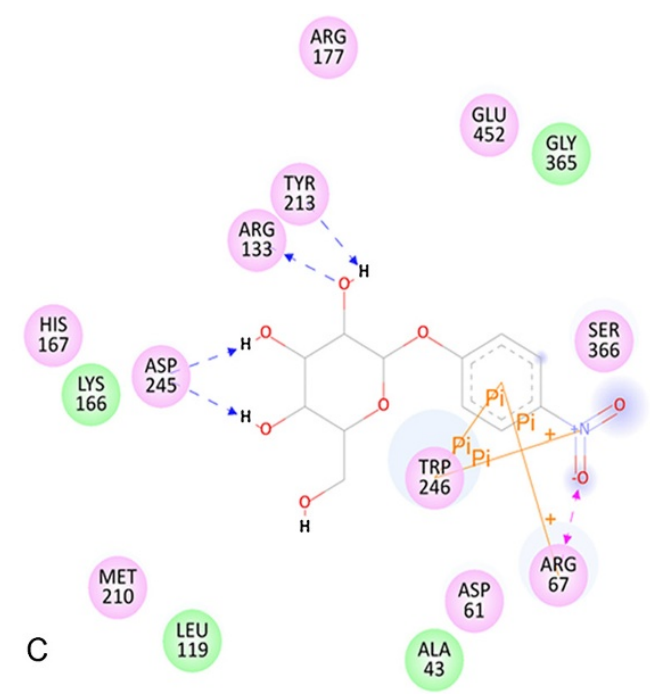

Figure 5 Structural models of $\beta$-glucosidases Unglu135B12 characterised in the present work and its substrate docking. A. The pNPG-binding model of Unglu135B12 derived from Thermotoga neapolitana $\beta$-glucosidase 3B (PDB ID 2X40). The three protein domains: $\alpha / \beta$ barrel, $\alpha / \beta$ sandwich and fibronectin-like, were coloured cyan, kelly and red, respectively. B. Closeup of the catalytic centre. $\mathbf{C}$. The key residues in the catalytic pocket around pNPG.

cellulase or hemicellulase will be beneficial for break the major bottleneck in industrial-scale conversion of cellulosic biomass into biofuels. Furthermore, discovery of other high preformance new monofunctional enzyme or multifuctional enzyme from our library is hopefully believed to provide more possibility for their applications in future industrial production. Besides, heterologously expressed functional enzyme by genetically modifying host organism could also be an effective tool in developing enzyme with desired properties.

\section{Methods}

\section{Animal ethics}

Care of laboratory animals and animal experimentation were performed in accordance with animal ethics guidelines and approved protocols. All animal experiments were performed according to the Hunan Community Rules of Animal Care with the permission number 38-61 of Hunan Agricultural University Veterinary Services (China).

\section{Metagenomic fosmid library construction and evaluation} Matagenomic DNA was extracted from rumen content of Xiangxi yellow cattle which were fed with sole fresh Miscanthus sinensis from 2.5 years old for 18 months. The pooled samples were collected and stored at $-80^{\circ} \mathrm{C}$ until DNA extraction.

Total DNA was extracted from the pooled samples as described before [18]. DNA fragments of about $36 \sim 48 \mathrm{~kb}$ were recovered from gel by electroelution for the library construction by using pCC2FOS ${ }^{\mathrm{TM}}$ Vector (Epicentre, USA). All of operation was following the manufacturer's instruction. Library clones were duplicated and stored in 96-well plates at $-80^{\circ} \mathrm{C}$.

Clones of fosmid library were cultured in 96-well plates containing $70 \mu \mathrm{l}$ lysogeny broth (LB) supplemented with chloramphenicol $(22.5 \mu \mathrm{g} / \mathrm{ml})$ at $37^{\circ} \mathrm{C}$ overnight. Then $\mathrm{LB}$ plates supplemented with esculin hydrate $(0.1 \%)$, ferric ammonium citrate $(0.25 \%)$ and chloramphenicol $(22.5 \mu \mathrm{g} / \mathrm{ml})$ were used for screening functional clones with $\beta$-glucosidase activity according to the method described by Eberhart et al [30]. Positive clones were detected by the formation of a black halo around the colonies after incubation at $37^{\circ} \mathrm{C}$ for 20-24 h. The strength of enzyme activity was initially decided by comparing the size of each black halo.

To evaluate the volume and stability of this library, we conducted the analysis of restriction endonuclease map with EcoR I and Hind III. Moreover, reliability of this library was detected by random sequencing.

\section{Subclone and sequence analysis}

Due to the length of insert sequence in each clone of fosmid library was about $40 \mathrm{~kb}$, it was too long to directly sequence the gene of $\beta$-glucosidase from positive clone. Therefore, Fosmid DNA of positive clone was extracted and digested by EcoR I and Hind III. Then DNA fragments around $1 \sim 5 \mathrm{~kb}$ length were ligated into the vector pUC19 (Promega, USA), and transformed into E. coli DH5 $\alpha$. After screening by the same method mentioned before, a positive subclone was detected and sequenced.

The open reading frames (ORF) of the aimed sequence were analyzed by DNAMAN. The domain architecture and conserved domain was analyzed by the online program SMART (http://smart.embl-heidelberg.de). The 
phylogenetic tree was constructed with MEGA4.0 software. Reliability of phylogenetic reconstruction was estimated by Boot-strapping values (1,000 replicates).

\section{Gene expression and protein purification}

Unglu135B12 was amplified by PCR using the primers 135B12F (5'-CGGAATTC TCCTTTGTCTACCTTTGT CAG-3') containing a EcoR I site (underlined) and 135B12R (5' -ATGCGGCCGCCGAGGTATTTACAAAA CACG-3') containing a Not I site (underlined), then the PCR fragments were digested with restriction endonucleases EcoR I and Not I and cloned into pET28a (+) digested with the same enzymes, resulting in the recombinant plasmid pET28a/Unglu135B12. For expression of Unglu135B12, pET28a/Unglu135B12 was transformed into $E$ coli BL21 (DE3), then was induced with $0.1 \mathrm{mmol} / \mathrm{L}$ IPTG at $25^{\circ} \mathrm{C}$ for $4.5 \mathrm{~h}$. Ni-NTA resin was used to purify the protein, and then dialyzed the protein with $20 \mathrm{mM}$ PBS buffer $(\mathrm{pH} 7.0)$ overnight at $4^{\circ} \mathrm{C}$. The protein before/after purification, flow-through and dialyzed fusion protein were analyzed by SDS-PAGE and western blot.

All protein samples $(15 \mu \mathrm{g})$ were separated by $8 \%$ SDSPAGE and transferred onto a PVDF membrane (Bio-Rad). Then anti-His Tag (6x) antibody was used to performed the immunoblots. The specifically stained bands were clearly visible by DAB staining.

\section{Enzyme assays and characterization of Unglu135B12}

The specific activity measurement was preformed as described by Feng [26], and one unit of $\beta$-glucosidase activity was defined as the amount of enzyme releasing $1 \mu \mathrm{mol} \mathrm{p}$ nitrophenol from p-nitrophenyl- $\beta$-glucopyranoside (pNPG). The amount of released p-nitrophenol was measured by the absorbance at $405 \mathrm{~nm}$ [31].

The temperature optimum for the freshly purified $\beta$-glucosidase activity was measured in a range from $25^{\circ} \mathrm{C}$ to $65^{\circ} \mathrm{C}$ by incubating Unglu135B12 at pH 5.0. The effect of $\mathrm{pH}$ on enzyme activity was evaluated at pHs ranged from 3.2 to 10 at optimal temperature. The thermostability of Unglu135B12 was evaluated by incubating the recombinant enzyme at $30^{\circ} \mathrm{C}, 40^{\circ} \mathrm{C}, 45^{\circ} \mathrm{C}$ and optimal temperature at $\mathrm{pH} 5.5$ for $1 \mathrm{~h}$, and then measuring the residual activity. The stability of Unglu135B12 against $\mathrm{pH}$ was assayed by measuring the residual activity of Unglu135B12 in the buffer at different pHs after incubation at $4^{\circ} \mathrm{C}$ for $24 \mathrm{~h}$.

Various cations $(3.5 \mathrm{mM})$ were used to investigate the effects of metal ions on the $\beta$-glucosidase. Effect of glucose on the $\beta$-glucosidase activity was also evaluated, which was studied by determining the activity of $\beta$-glucosidase towards pNPG in presence of dose-dependent glucose (0 mM, $40 \mathrm{mM}, 90 \mathrm{mM}, 160 \mathrm{mM}, 280 \mathrm{mM}, 375 \mathrm{mM}$, $444 \mathrm{mM}, 500 \mathrm{mM}, 660 \mathrm{mM}, 800 \mathrm{mM})$.
To determine the $K_{m}$ and Vmax values, reactions were acted under optimal condition with pNPG ranging from 0 to $8 \mathrm{mmol} \mathrm{l}^{-1}$ according to the double-reciprocal plot method. All measurements were analyzed in triplicate.

\section{Homology modeling and substrate docking}

The translation product of aimed sequence unglu135B12 was further analyzed for protein domains using the PfamA database [32]. Model of $\beta$-glucosidases unglu135B12 were obtained from the SWISS-MODEL server (http:// swissmodel.expasy.org/) using the coordinates of known $\beta$-glucosidase structure (PDB ID 2X40: $\beta$-glucosidase 3B from Thermotoga neapolitana) as the template. The lowest-energy model was chosen for the docking of the substrate of pNPG using Discovery Studio LibDock.

\section{Additional file}

Additional file 1: Table S1. The result of random sequencing.

\section{Competing interests}

The authors declare that they have no competing interests.

\section{Authors' contributions}

$L Y D, T Y$ and $L X Y$ devised the method and designed the study. $L Y D, L N, Y H$ and $Z \mathrm{H}$ carried on the experimental work. LYD and $Y Y$ analyzed the data. LYD, YY, TY and LXY wrote the manuscript. All authors contributed to the manuscript. All authors read and approved the final manuscript.

\section{Acknowledgments}

This research was supported by the International Scientific and Technological Cooperation Project (2010DFA62510), the Program for Changjiang Scholars and Innovative Research Team in University (IRT0963), Hunan Provincial Innovation Foundation for Postgraduate (CX2013B299) and The Construct Program of the Key discipline in Hunan Province.

\section{Author details}

${ }^{1}$ College of Bioscience and Biotechnology, Hunan Agricultural University, Changsha 410128, China. ${ }^{2}$ Hunan Agricultural Bioengineering Research Institute, Changsha 410128, China. ${ }^{3}$ College of Life Science, Hunan Normal University, Changsha 410181, China. ${ }^{4}$ Departments of Physiology, Biochemistry, and Molecular Cell Biology, Institute of Medical Science, Shanghai Jiao Tong University School of Medicine, Shanghai 200025, China.

Received: 9 July 2014 Accepted: 24 September 2014

Published: 2 October 2014

\section{References}

1. Sims RE, Mabee W, Saddler JN, Taylor M: An overview of second generation biofuel technologies. Bioresour Technol 2010, 101:1570-1580.

2. Yi Z, Ruihong Z: Overview of biomass pretreatment for cellulosic ethanol production. Int J Agric Biol Eng 2009, 2:51-69.

3. Shumny VK, Veprev SG, Nechiporenko NN, Goryachkovskaya TN, Slynko NM, Kolchanov NA, Peltek SE: A new variety of Chinese silver grass (Miscanthus sinensis anderss.): a promising source of cellulose containing raw material. Russ J Genet Appl Res 2011, 1:29-32.

4. Chesson ASC, Dalgarno K, King TP: Degradtion of ioslated grass mesophyll, epidermis, and fiber cell walls in the rumen and by cellulolytic rumen bacteria in axenic culture. J App/ Bacteriol 1986, 60:327-336.

5. Lynd LR, Weimer PJ, vanZyI WH, Pretorius IS: Microbial cellulose utilization: fundamentals and biotechnology. Microbiol Mol Biol Rev 2002, 66:506-577.

6. Bokkenheuser VD, Shackleton $\mathrm{CH}$, Winter J: Hydrolysis of dietary flavonoid glycosides by strains of intestinal bacteroides from humans. Biochem J 1987, 248:953-956. 
7. Freer SN: Kinetic characterization of a beta-glucosidase from a yeast, Candida wickerhamii. J Biol Chem 1993, 268:9337-9342.

8. Shallom D, Shoham Y: Microbial hemicellulases. Curr Opin Microbiol 2003, 6:219-228.

9. Dahai G, Shishir PSC, Tongjun L, Spencer H, Krishne G, Phillip B, Bruce ED, Venkatesh B: Strategy for identification of novel fungal and bacterial glycosyl hydrolase hybrid mixtures that can efficiently saccharify pretreated lignocellulosic biomass. Bioenerg Res 2010, 3:67-81.

10. Saha BC, Freer SN, Bothast RJ: Production, purification, and properties of a thermostable beta-glucosidase from a color variant strain of aureobasidium pullulans. Appl Environ Microbiol 1994, 60:3774-3780.

11. Brulc JM, Antonopoulos DA, Miller ME, Wilson MK, Yannarell AC, Dinsdale EA, Edwards RE, Frank ED, Emerson JB, Wacklin P, Countinho PM, Henrissat $B$, Nelson KE, White BA: Gene-centric metagenomics of the fiber-adherent bovine rumen microbiome reveals forage specific glycoside hydrolases. Proc Natl Acad Sci U S A 2009, 106:1948-1953.

12. Kristen MD, Martin A, D'haeseleer P, Julian LF, Amitha R, Philip H, Steven WS, Jean SVG, Whendee LS, Blake AS, Terry CH: Strategies for enhancing the effectiveness of metagenomic-based enzyme discovery in lignocellulolytic microbial communities. Bioenerg Res 2010, 3:146-158.

13. Banik JJ, Brady SF: Recent application of metagenomic approaches toward the discovery of antimicrobials and other bioactive small molecules. Curr Opin Microbiol 2010, 13:603-609.

14. Tuffin M, Anderson D, Heath C, Cowan DA: Metagenomic gene discovery: how far have we moved into novel sequence space? Biotechnol J 2009. 4:1671-1683.

15. Bao L, Huang Q, Chang L, Sun Q, Zhou J, Lu H: Cloning and characterization of two beta-glucosidase/xylosidase enzymes from yak rumen metagenome. App/ Biochem Biotechnol 2012, 166:72-86.

16. Jiang CJ, Chen G, Huang J, Huang Q, Jin K, Shen PH, Li JF, Wu B: A novel beta-glucosidase with lipolytic activity from a soil metagenome. Folia Microbiol (Praha) 2011, 56:563-570.

17. Wang Q, Qian C, Zhang XZ, Liu N, Yan X, Zhou Z: Characterization of a novel thermostable beta-glucosidase from a metagenomic library of termite gut. Enzyme Microb Technol 2012, 51:319-324.

18. Li Y, Hu L, Xue G, Liu H, Yang H, Zhu Y, Tian Y, Lu X: Comparison of bacterial diversity in large intestine of Xiangxi yellow cattle (Bos taurus) associated with different diet: fresh Miscanthus sinensis and mixed forage. Afr J Microbiol Res 2012, 6:5965-5974.

19. Del-Pozo MV, Fernandez-Arrojo L, Gil-Martinez J, Montesinos A, Chernikova TN, Nechitaylo TY, Waliszek A, Tortajada M, Rojas A, Huws SA, Golyshina OV, Newbold CJ, Polaina J, Ferrer M, Golyshin PN: Microbial beta-glucosidases from cow rumen metagenome enhance the saccharification of lignocellulose in combination with commercial cellulase cocktail. Biotechnol Biofuels 2012, 5:73.

20. Mrázek JTK, Avguštin G, Kopečný J: Diet-dependent shifts in ruminal butyrate-producing bacteria. Folia Microbiol (Praha) 2006, 51:294-298.

21. Mariat D, Firmesse O, Levenez F, Guimaraes V, Sokol H, Dore J, Corthier G, Furet JP: The firmicutes/bacteroidetes ratio of the human microbiota changes with age. BMC Microbiol 2009, 9:123.

22. Martens EC, Koropatkin NM, Smith TJ, Gordon Jl: Complex glycan catabolism by the human gut microbiota: the bacteroidetes sus-like paradigm. J Biol Chem 2009, 284:24673-24677.

23. Ferrer M, Ghazi A, Beloqui A, Vieites JM, Lopez-Cortes N, Marín-Navarro J, Nechitaylo TY, Guazzaroni ME, Polaina J, Waliczek A, Chernikova TN, Reva ON, Golyshina OV, Golyshin PN: Functional metagenomics unveils a multifunctional glycosyl hydrolase from the family 43 catalysing the breakdown of plant polymers in the calf rumen. PLoS One 2012, 7:e38134.

24. Eijsink VG, Gaseidnes S, Borchert TV, van den Burg B: Directed evolution of enzyme stability. Biomol Eng 2005, 22:21-30.

25. Cesar Mateo JMP, Gloria FL, Jose MG, Roberto FL: Improvement of enzyme activity, stability and selectivity via immobilization techniques. Enzyme Microb Technol 2007, 40:1451-1463.

26. Feng Y, Duan CJ, Liu L, Tang JL, Feng JX: Properties of a metagenome-derived beta-glucosidase from the contents of rabbit cecum. Biosci Biotechnol Biochem 2009, 73:1470-1473

27. Belancic A, Gunata Z, Vallier MJ, Agosin E: Beta-glucosidase from the grape native yeast debaryomyces vanrijiae: purification, characterization, and its effect on monoterpene content of a Muscat grape juice. J Agric Food Chem 2003, 51:1453-1459.
28. Zanoelo FF, Polizeli ML, Terenzi HF, Jorge JA: Beta-glucosidase activity from the thermophilic fungus scytalidium thermophilum is stimulated by glucose and xylose. FEMS Microbiol Lett 2004, 240:137-143.

29. Fang Z, Fang W, Liu J, Hong Y, Peng H, Zhang X, Sun B, Xiao Y: Cloning and characterization of a beta-glucosidase from marine microbial metagenome with excellent glucose tolerance. J Microbiol Biotechnol 2010, 20:1351-1358.

30. Eberhart B, Cross DF, Chase LR: Beta-glucosidase system of neurospora crassa. I. Beta-glucosidase and cellulase activities of mutant and wildtype strains. J Bacteriol 1964, 87:761-770.

31. Jatinder Kaur BSC, Badhan AK, Ghatora SK, Harvinder SS: Purification and characterization of $\beta$-glucosidase from Melanocarpus sp. MTCC 3922. Electron J Biotechnol 2007, 10:260-270.

32. Bateman A, Coin L, Durbin R, Finn RD, Hollich V, Sonnhammer EL: The Pfam protein families database. Nucleic Acids Res 2004, 32:D138-D141.

doi:10.1186/1472-6750-14-85

Cite this article as: Li et al:: Cloning and characterization of a new $\beta$-Glucosidase from a metagenomic library of Rumen of cattle feeding with Miscanthus sinensis. BMC Biotechnology 2014 14:85.

\section{Submit your next manuscript to BioMed Central and take full advantage of:}

- Convenient online submission

- Thorough peer review

- No space constraints or color figure charges

- Immediate publication on acceptance

- Inclusion in PubMed, CAS, Scopus and Google Scholar

- Research which is freely available for redistribution

Submit your manuscript at www.biomedcentral.com/submit
C) Biomed Central 